\title{
Examination of Mathematical Thinking Skills of University Students Attending Universities Intercultural Competition
}

\author{
Bülent Arslantaş ${ }^{1}$, Faruk Malbeleği ${ }^{2}$, Mehmet İnan ${ }^{3}$
}

${ }^{1}$ Istanbul Technical University, arslantasb@gmail.com

${ }^{2} \mathrm{PhD}$ student, fmalbelegi@gmail.com

${ }^{3}$ Marmara University, minan@ marmara.edu.tr

Received: 19.03.2018

doi: $10.30655 /$ besad. 2018.8
Accepted: 26.04.2018 Online Published: 30.09.2018

url: https://doi.org/10.30655/besad.2018.8

\begin{abstract}
The aim of the research was examining the mathematical thinking skills of university students participating in intercollegiate team competitions in various fields. The research was designed as a survey model. The study sample was established by volunteered licensed university students $(N=187)$ participating in University Sports Federation of Turkey tournaments and Universities' League (UNILIG). The "Mathematical Thinking Scale" developed by Ersoy (2012) was used in the research. Computer statistical programs were used for statistical analysis in the study. Percentage, frequency analysis was used for descriptive analyzes in data analysis. Mann Whitney-U and Kruskal-Wallis tests were performed for nonparametric statistical applications to measure the differences between the groups. According to findings; men athletes have more mathematical thinking points then women. Athletes dealing with soccer are more likely to score mathematical thinking skills (rank average of 143.77) than the athletes in other disciplines. There is also a statistically significant difference in the mathematical thinking scale subscales among the athletes who perform team sports ( $p<0.05)$. According to these results, university students who are interested in futsal have higher test scores in terms of mathematical thinking skills for all sub dimensions. These differences in basketball, volleyball, soccer and soccer team sports are valid for higher-order thinking tendencies, reasoning, mathematical thinking, and problem-solving skills, which are sub-dimensions of the mathematical thinking scale. Also athletes who perform their branches 0-5 years have more mathematical thinking points then other groups.
\end{abstract}

Keywords: Thinking Skills, Mathematical Thinking, University Students

\section{Üniversitelerarası Müsabakalara Katılan Üniversite Öğrencilerinin Matematiksel Düşünme Becerilerinin İncelenmesi}

\section{$\ddot{O} \mathbf{z}$}

Bu araştırmanın amacı çeşitli branşlarda üniversiteler arası takım müsabakalarına katılan üniversite öğrencilerinin matematiksel düşünme becerilerinin çeşitli değişkenler açısından incelenmesidir. Araştırma tarama modeli olarak tasarlanmıştır. Araştırmanın örneklemi Türkiye Üniversite Sporları Federasyonu'nu ve üniversiteler ligine (ünilig) katılan lisanslı 187 gönüllü ( $n=187$ ) üniversite ögrencisinden oluşmaktadır. Araştırmada, Ersoy (2012) tarafindan geliştirilen "Matematiksel Düşünme Ölçeği” kullanılmıştır. Veri analizinde betimsel analizler için yüzde, frekans analizi kullanılmıştır. Gruplar arası farklılıkların ölçülmesi için non-parametrik istatistik uygulamalardan Mann Whitney-U ve Kruskal-Wallis testleri uygulanmıştır. Elde edilen bulgulara göre; Salon Futbolu ile ilgilenen sporcuların diğer branşlarda yer alan sporculara göre matematiksel düşünme beceri puanları (sıra ortalaması 143,77) daha yüksektir. Takım sporları yapan sporcular arasında matematiksel düşünme ölçeği alt boyutlarında da anlamlı farklılık vardır $(p<, 05)$. Bu sonuçlara erkek sporcular kadın sporculara göre 
daha yüksek matematiksel düşünme puanlarına sahiptirler. Spor branşı değişkenine göre salon futbolu ile ilgilenen üniversite ögrencilerinin matematiksel düşünme becerileri, matematiksel düşünme ölçeğinin tüm alt boyutlar için basketbol, voleybol ve futbol sporlarlyla ilgilenen sporculara göre daha yüksektir. Spor branşlarıyla ilgili farklılıklar matematiksel düşünme ölçeğinin alt boyutları olan üst düzey düşünme eğilimi, akll yürütme, matematiksel düşünme becerisi ve problem çözme becerisi için geçerlidir. Spor yll değişkenine göre 0-5 yılları arasında spor yapan katılımcıların puanları daha yükse bulunmuştur.

Anahtar kelimeler: Düşünme becerileri, matematiksel düşünme, üniversite ögrencileri

\section{Giriş}

Teknolojik gelişmelerle birlikte daha önceki kuşakların karşılaşmadığı yeni problemlerle karşılaşılan günümüz dünyasında, matematiğe değer veren, matematiksel düşünme gücü gelişmiş, matematiği modelleme ve problem çözmede kullanabilen bireylere her zamankinden daha çok ihtiyaç duyulmaktadır (MEB, 2013).

Matematik eğitiminde uluslararası düzeyde kabul gören bir merkez olan "National Council of Teachers of Mathematics" (NCTM) kurumunun çalışmaları bugün dünyada matematik eğitimi alanında çalışan pek çok araştırmacı için referans kabul edilmektedir (Cai, 2003). NCTM tarafindan son olarak 2000 yılında, "Principles and Standards of School Mathematics" (PSSM) adlı bir doküman yayımlanmıştır (NCTM, 2000). Bu dokümanda anaokulundan 12. sınıfın sonuna kadar okul matematiğin genel prensiplerinin neler olması gerektiğgi ve matematiksel içerik ve süreçlerin hangi standartları sağlaması gerektiği açıklanmaktadır.

Matematik öğretiminde öğrencilere kazandırılması hedeflenen temel becerilerden biri Matematiksel Düşünmedir (MD). Bu becerinin kazandırılmasının önemi matematik eğitiminde önde gelen kuruluşlardan biri olan Amerikan Ulusal Matematik Öğretmenleri Konseyi (The National Council of Teachers of Mathematics [NCTM] ) tarafindan da vurgulanmaktadır. NCTM'in Değerlendirme Standartları ise (Assessment Standards for School Mathematics) 1990’lı yılların ortalarında başlamıştır. NCTM tarafından yayınlanan Prensipler ve Standartlar 'da günlük hayatta ve iş yaşamında matematiği anlama ve kullanabilme ihtiyacının giderek arttığ1 ve sağlıktan grafik tasarımına kadar pek çok mesleki alanda matematiksel düşünme ve problem çözmeye daha fazla ihtiyaç duyulduğu belirtilmektedir (NCTM, 2000). Matematiğin yaşamımdaki önemi ve bireyin matematiğe olan ihtiyacı göz önünde bulundurulduğunda, bireyin matematiksel kapasitenin olabildiğince artırılmasına çalışılmalı ve en önemlisi çocuklara küçük yaştan itibaren matematiksel düşünme yönünde eğitim uygulanmalıdır (Umay, 1996).

Henderson (2002) matematiksel düşünmeyi, problem çözme sürecinde uygun matematiksel teknikleri, kavramları ve süreçleri doğrudan ya da dolaylı kullanmak olarak tanımlamıştır. Ferri (2003) matematiksel düşünmeyi, problemin cevabından öte problemin tüm yönleriyle ele 
alınarak incelenmesi olarak ifade etmiştir. Umay (1996) matematiksel düşünmeyi aynı sonuca giden çözüm yollarından en iyi ve kısa olanı olarak ifade etmiş ve matematiksel düşünmenin kesinlik içerdiğini belirtmiştir. Tall (1995) ise, matematiksel düşünmeyi, bireyin çevresindeki nesneleri algılama ve onların aralarındaki ilişkiyi anlamlı kılma çabası olarak nitelendirmiştir.

Bireyler, yaşamlarının her aşamasında karşılaştıkları olay ve olguları çözümlemede, farkında olarak ya da olmayarak, matematiksel düşüncelerini kullanırlar. Bir başka ifadeyle matematiksel düşünme yalnızca matematikçilere has olan bir düşünme biçimi değildir. Aksine günümüzde her meslek sahibinin ihtiyaç duyduğu ve yaşamına adapte etmesi gereken bir düşünme biçimidir. Yaşamı boyunca birey hayatının her alanında, okulda, işte, problem çözmeye çalışır Bunun için de matematiksel düşünmeye tartışmasız gereksinim duyar (Blitzer, 2003). Matematiksel düşünme aynı zamanda, günümüzün modern eğitim anlayışı çerçevesinde bireylerde olması arzulanan niteliklerin gelişimine katkı sağlar (Bukova ve Alkan, 2003). Bu nedenle hangi ilgi alanında ya da meslekte olursa olsun, bireylerin geliştirmesi gereken bir nitelik olarak düşünülmelidir.

Her düşünme becerisinde olduğu gibi matematiksel düşünmede de algılarımızdan hareket ederek bir ürüne ulaşma çabası vardır. Bu çaba sırasında kullanılan yaklaşımlarda bazı bireysel farklılıklar olabilir. Sevgen (2002) matematiksel düşünce insanların yaşamlarında karşılaştıkları olaylara, sistematik, doğru ve çabuk yoldan anlamlandırmalarını sağlayan önemli bir kavram olarak tanımlamıştır.

Matematiksel düşünme insanların karşılaştıkları olaylara sistematik ve hızlı yaklaşmasıdır. "Eğer bir sorunla karşılaşılmışsa varsa, bu soruna karşı muhakkak bir çözüm yolu vardır” düşüncesi bireyi çözüm arayışı içerisine sevk eder (Sevgen, 2002). Bu arayış bireyi sistematik düşünmeye zorlar. Burada matematik devreye girmektedir. Matematiği yalnızca sayı ve rakamlardan ibaret görmek bireyi sınırlandırır. Matematik analiz, istatistik, inceleme, soyutlaştırma, somutlaştırma olarak düşünülebilir. Bu süreçler karşılaşılan problemi sistematik hale getirme ve çözüme kavuşturmaya olanak sağlar.

Matematik bilimini yaşamın tüm alanlarında görmek mümkündür. Spor ile matematik birçok yönden ilişkilendirilebilir. Örneğin herhangi bir spor dalında taktik çalışmalar yapılırken takım oyuncularının nasıl hareket edeceği geometrik yöntemlerle açıklanabilir. Yine futbolda dar alanda üçgen kurarak paslaşmak ya da hentbolda hücumu organizasyonunu yarım daireler üzerine kurmak, matematiğin sporla ilişkisini basitçe ifade edebilir.

Sportif faaliyetlerin, özellikle sürekli icra edilen antrenmanların eğitim-öğretime, bireyin sosyal gelişimine ne düzeyde katkıda bulunduğu, spor yapan öğrenci ile spor yapmayan öğrencinin aynı 
ortam ve şartlar altında problem çözme, strese karşı koyma ve kişisel uyum becerilerini ne düzeyde gerçekleştirebildikleri, ayrıca akademik başarı düzeylerinin seviyesi, ebeveyn, spor ve eğitim bilimciler için önemli kaynak noktalarından birini oluşturmaktadır (Türkçapar, 2009). Spor, bireylerin fiziksel, zihinsel, duygusal ve sosyal yönden gelişimlerini sağlayan, bilgi, beceri ve liderlik yeteneklerini geliştiren bir araçtır. Spor, insanın kendi kendisini disipline etmesine karşılaşacağ 1 psikolojik ve fizyolojik sorunların üstesinden gelmesine yardım eder.

Spor ve fiziksel aktiviteye katılımın psikolojik özelliklerin yanında insanların kişilik gelişimleri üzerine de bazı etkileri olduğu bilinmektedir. Küçük ve Koç (2004), spora katılımın insanların kişilik gelişimleri üzerine etkileri değerlendirildiği çalışmalarında, insanların kişilik gelişimlerinin desteklenmesinde spora katılımın büyük bir öneme sahip olduğunu vurgulamaktadırlar.

Düzenli spor yapma insanın hayatını birçok yönüyle olumlu yönde etkilemektedir. Düzenli sporun beden gelişimine ve sosyal gelişime katkıları olduğu gibi insan zekâsının değişik yönlerine de olumlu yönde katkı sağlayabileceği düşünülmektedir (Metan ve Küçük, 2017). Düzenli olarak spor yapmanın, özellikle takım sporlarının depresyon ve problem çözme becerisi üzerine olumlu etkisi olduğu ifade edilmektedir (Anan ve Ataoğlu, 2010).

Takım sporları, organizasyon yeteneğini, olumlu etkileşim kapasitesini ve çok yönlü düşünme tarzını geliştirmede faydalı olabilir (Brown, 1965). Spor dalının türü, içerisinde barındırdığı bir takım psikolojik özellikleri (motivasyon, bireysel mücadele, takım ruhu, konsantrasyon ve motivasyon vb.) nedeniyle bireyin de psikolojik ve duygusal durumunu olumlu yönlerde etkileyebilir (Salar, Hekim, Tokgöz, 2012).

Literatürde matematiksel düşünmenin yaşamın merkezinde olması fikrini akla getirirken, spor ve özellikle üniversitelerde öğrenim gören ve aynı zamanda bir spor takımında oynayan yarışmacı sporcuların düşünme becerilerinin hangi düzeyde olduğu araştırmaya değer bulunmuştur. Araştırmanın amacı, üniversite öğrencilerinin akademik olarak matematiksel düşünme yetkinliği, yapmakta oldukları spor branşları yönünden hangi düzeyde farklılıklar gösterdiğinin araştırılmasıdır. Araştırmada üniversiteler arası müsabakalara katılan öğrencilerin matematiksel düşünme becerilerinin cinsiyet, devam ettikleri üniversite türü, yaş, spor branşları ve spora devam ettikleri yıl değişkenleri bakımından herhangi bir farklılık olup olmadığı sorusuna cevap aranmıştır. 


\section{Yöntem}

Araştırma "tarama modeli” olarak tasarlanmıştır. Tarama modelleri, geçmişte ya da hali hazırda var olan bir durumu olduğu gibi betimlemeyi amaçlayan araştırma türüdür. Araştırmaya konu olay, kişi ya da nesne, kendi şartları içerisinde ve olduğu gibi tanımlanmaya çalışılır. Herhangi bir değiştirme ya da etkileme çabası gösterilmez (Karasar, 2009).

Araştırmanın örneklemini Türkiye Üniversite Sporları Federasyonu'nun 2015-2016 y1l üniversiteler arası İstanbul ili basketbol 1.lig, futbol 1.lig, voleybol 2.lig ve salon futbolu üniversiteler ligi (ünilig) müsabakalarına katılan 187 sporcu oluşturmaktadır.

Araştırmada, Ersoy (2012) tarafından geliştirilen "Matematiksel Düşünme Ölçeği" kullanılmıştır. "Matematiksel Düşünme Ölçeği” 20 olumlu, 5 olumsuz olmak üzere toplam 25 madden oluşmaktadır. Ölçekte yer alan olumsuz maddeler tersten kodlanmıştır. Ölçek 5'li likert tipi olarak hazırlanmıştır. Ölçekteki olumlu maddeler "Tamamen katılıyorum=5", "Kısmen atıliyorum=4", “Kararsız=3”, "Katılmıyorum=2”, "Hiç Katılmıyorum=1” şeklinde 'den 1'e doğru puanlanmış, olumsuz ifadeler ise "Tamamen atılıyorum=1"den "Hiç Katılmıyorum=5" olacak şekilde 1'den 5'e doğru puanlanmıştır. Ölçekten alınacak en yüksek puan 125, en düşük puan $25^{\prime}$ dir. Ölçeği geliştiren araştırmacının yaptığı analiz sonucunda ölçeğin güvenirliği ,78 olarak hesaplanmıştır. Bu değer ölçeğin güvenilir bir ölçme aracı olarak kullanılabileceğini göstermektedir. Ölçekten alınan puanlar arttıkça matematiksel düşünme düzeyinin arttı̆̆ı, puanlar azaldıkça matematiksel düşünme düzeyinin azaldığı ortaya çıkmaktadır.

Ölçek, üniversite sporları federasyonunun ilan ettiği müsabaka takvimine göre karşılaşacak olan üniversite takımlarına müsabaka öncesinde takım sorumlusundan gerekli izinler alınarak ve takım oyuncularına gerekli açıklamalar doğrultusunda yaptırılmıştır. Ölçeğin uygulanmasında öğrencilere yeteri kadar süre verilmiş ve sorulara titizlikle cevap verilmesi sağlanmıştır.

Araştırmada istatistiksel analizler için bilgisayarlı istatistik programları kullanılmıştır. Verilerin analizlerinde betimsel analizler için yüzde, frekans analizi kullanılmıştır. Veri setinin normal dağılım gösterip göstermediğinin anlaşılması için yapılan Kolmogorov-Smirnov testi sonuçlarına göre verilerin normal dağılmadığı sonucuna varılmıştır.

Tablo 1 Normal Dağılım Testi - Kolmogorov-Smirnov

\begin{tabular}{cccc}
\hline & İstatistik & Serbeslik Değeri & $\mathbf{p}$ \\
\hline Toplam &, 168 & 187 &, 000 \\
\hline
\end{tabular}

Bu nedenle gruplar arası farklılıkların ölçülmesi için normal dağılım ve homojenlik koşulları yerine gelmediğinden non-parametrik testler uygulanmıştır. Non-Parametrik istatistik 
uygulamalardan Mann Whitney-U ve Kruskal-Wallis testleri gruplar arası farklılığın ölçülmesi için uygulanmıştır. Sonuçlar 0,05 anlamlılık düzeyinde değerlendirilmiştir.

\section{Bulgular}

Araştırmaya katılan sporcuların 47'si kadın, 140'1 erkek katılımcıdan oluşmaktadır. Bu katılımcılardan 104'ü devlet üniversitesinde, 83'ü ise özel üniversitede öğrenim görmektedir. Katılımcıların 46'sı futbol, 34'ü basketbol 60'1 salon futbolu, 47'si ise voleybol branşlarını yapmaktadırlar. Katılımcıların yaş gruplarına bakıldı̆̆ında 68 sporcu 17-20 yaş aralığında, 89'u 21-23 yaş aralığında, 30’u ise 24-27 yaş aralığındadır. Devam ettikleri sporu yapma sürelerine bakıldığında 81 öğrenci 0-5, 76 öğrenci 6-10, 29 öğrenci ise 11 ve üzeri yı1 süreyle yaptığı sporla ilgilenmektedir. Araştırmanın ilk sorusu olan cinsiyet değişkeniyle ilgili veriler Tablo 2'de görülmektedir.

Tablo 2 Matematiksel Düşünme Ölçeğinden Alınan Toplam Puanların Cinsiyet Değişkenine Göre Karşılaştırılmasına İlişkin Tablo

\begin{tabular}{llllll}
\hline Grup & N & Sira Ort. & Siralar Top. & U & p \\
\hline Kadın & 47 & 50,10 & 2354,5 & 1226,5 &, 000 \\
Erkek & 140 & 108,74 & 15223,5 & & \\
\hline
\end{tabular}

Tablo incelendiğinde araştırmaya katılan sporcuların cinsiyet değişkenlerine göre matematiksel düşünme ölçeğinden aldıkları puanlar açısından istatistiksel olarak anlamlı farklılık görülmektedir $(\mathrm{p}<, 05)$. Erkek katılımcıların sıra ortalamaları 108,74 iken kadın katılımcıların sıra ortalamaları 50,10 olarak tespit edilmiştir.

Tablo 3 Matematiksel Düşünme Ölçeğinden Alınan Toplam Puanların Üniversite Türü Değişkenine Göre Karşılaştırılmasına İlişkin Tablo

\begin{tabular}{llllll}
\hline Grup & N & Sira Ort. & Siralar Top. & U & p \\
\hline Devlet & 104 & 100,57 & 10459,50 & 3632,5 &, 063 \\
Özel & 83 & 85,77 & 7118,50 & & \\
\hline
\end{tabular}

Araştırmaya katılan sporcuların devam ettikleri üniversite türüne göre matematiksel düşünme ölçeğinden aldıkları puanlar istatistiksel olarak farklılık göstermemektedir $(p<, 05)$. Devlet üniversitesine devam eden öğrencilerin siralar ortalaması $(100,57)$, özel üniversitelere devam eden öğrencilere $(85,77)$ göre yüksek olmasına rağmen bu fark istatistiksel olarak anlamlı değildir. 
Tablo 4 Matematiksel Düşünme Ölçeğinden Alınan Toplam Puanların Spor Dalı Değişkenine Göre Karşılaştırılmasına İlişkin Tablo

\begin{tabular}{lllll}
\hline Grup & N & Sira Ort. & Chi-Square & p \\
\hline Futbol & 46 & 77,70 & 86,159 &, 000 \\
Basketbol & 34 & 88,93 & & \\
Salon Futbolu & 60 & 143,77 & & \\
Voleybol & 47 & 50,10 & & \\
\hline
\end{tabular}

Tabloda görüldüğü gibi araştırmaya katılan sporcuların spor dalı değişkenlerine göre matematiksel düşünme ölçeğinden aldıkları toplam puanlara göre istatistiksel olarak farklılık gözükmektedir $(\mathrm{p}<, 05)$. Bu farkın hangi gruplar arasında olduğunun anlaşılması için MannWhitney $\mathrm{U}$ testine bakılmıştır. Buna göre salon futboluna devam eden öğrencilerin puanları $(143,77)$ diğer branşlara göre anlamlı derecede yüksektir. Ayrıca futbol $(77,70)$ ve basketbol $(88,93)$ sporuyla ilgilenen öğrencilerin puanları voleybol $(50,10)$ sporuyla ilgilenenlere göre anlamlı derecede daha yüksektir.

Tablo 5 Takım sporları yapan sporcular arasında matematiksel düşünme ölçeği alt boyutlarından alınan puanlara ilişkin tablo

\begin{tabular}{llllll}
\hline Alt Boyutlar & Grup & N & Sıra Ort. & Chi-Square & p \\
\hline Üst Düzey Düşünme Eğilimi & Futbol & 46 & 81,36 & 84,590 &, 000 \\
& Basketbol & 34 & 86,26 & & \\
& Salon Futbolu & 60 & 143,00 & & \\
& Voleybol & 47 & 49,41 & &, 000 \\
& Futbol & 46 & 75,93 & 87,474 & \\
& Basketbol & 34 & 88,96 & & \\
& Salon Futbolu & 60 & 144,32 & & \\
& Voleybol & 47 & 51,10 & & \\
& Futbol & 46 & 78,29 & 84,121 & \\
& Basketbol & 34 & 88,76 & & \\
& Salon Futbolu & 60 & 143,11 & & \\
& Voleybol & 47 & 50,47 & & \\
\hline Problem Çözme & Futbol & 46 & 73,62 & 77,428 & \\
& Basketbol & 34 & 92,79 & & \\
& Salon Futbolu & 60 & 141,24 & & \\
& Voleybol & 47 & 54,51 & & \\
& & & & & \\
& & & & \\
& &
\end{tabular}

Matematiksel düşünme ölçeğinin alt boyutları incelendiğinde üst düzey düşünme, akıl yürütme, matematiksel düşünme becerisi ve akıl yürütme becerilerinin tümünde salon futboluyla ilgilenen sporcuların aldıkları puanlar diğer branşlara göre anlamlı derecede yüksektir $(p<, 05)$. Ölçek toplam puanından alınan sonuçlar alt boyutlar için de geçerlidir.

Tablo 6 Matematiksel Düşünme Ölçeğinden Alınan Toplam Puanların Yaş Değişkenine Göre Karşılaştırılmasına İlişkin Tablo

\begin{tabular}{lllll}
\hline Grup & N & Sira Ort. & Chi-Square & p \\
\hline $17-20$ & 68 & 72,82 & 16,639 &, 000 \\
$21-23$ & 89 & 104,59 & & \\
$23-27$ & 30 & 110,58 & & \\
\hline
\end{tabular}


Araştırmaya katılan sporcuların yaş değişkenlerine göre matematiksel düşünme ölçeğinden aldıkları toplam puanlar istatistiksel olarak farklılık göstermektedir $(\mathrm{p}<, 05)$. Bu farkın hangi gruplar arasında olduğunun anlaşılması için Mann-Whitney U testine bakılmıştır. Buna göre yaş grubu yükseldikçe alınan puanlar da artmaktadır. 23 yaş üstü gruptaki öğrencilerin aldıkları toplam puanlar $(110,58)$ diğer gruplara göre anlamlı derecede yüksektir. Aynı zamanda 21-23 arasındaki öğrencilerin puanları $(104,59), 17-20$ yaş grubunun puanlarına $(72,82)$ göre daha yüksek çıkmıştır.

Tablo 7 Matematiksel Düşünme Ölçeğinden Alınan Toplam Puanların Spor Yılı Değişkenine Göre Karşılaştırılmasına İlişkin Tablo

\begin{tabular}{lllll}
\hline Grup & N & Sira Ort. & Chi-Square & p \\
\hline $0-5$ & 81 & 112,43 & 24,905 &, 000 \\
$6-10$ & 76 & 74,45 & & \\
11 üzeri & 29 & 99,32 & & \\
\hline
\end{tabular}

Araştırmaya katılan sporcuların spor yılı değişkenlerine göre matematiksel düşünme ölçeğinden aldıkları toplam puanlar istatistiksel olarak farklılık göstermektedir $(\mathrm{p}<, 05)$. Bu farkın hangi gruplar arasında olduğunun anlaşılması için Mann-Whitney U testine bakılmıştır. Buna göre 0-5 yıl arası spor yapan öğrencilerin aldıkları toplam puanlar diğer gruplara göre anlamlı derecede yüksektir.

\section{Tartışma ve Sonuç}

$\mathrm{Bu}$ araştırmada Türkiye Üniversite Sporları Federasyonu'nu ile üniversiteler ligi (ünilig) müsabakalarına katılan ve takım sporu yapan lisanslı sporcuların matematiksel düşünme düzeylerinin cinsiyet, üniversite türü, spor dalı, yaş ve spor yılı değişkenlerine göre belirlenmesi amaçlanmıştır.

Araştırmanın sorularından birisi olan cinsiyet değişkenine ilişkin veriler incelendiğine erkek sporcuların kadın sporculara göre daha yüksek matematiksel düşünme becerisi puanları aldığ 1 görülmüştür. Türkçapar'ın (2009) beden eğitimi ve spor yüksekokuluna devam eden öğrencilerin problem çözme becerilerini incelediği çalışmasında erkek öğrencilerin problem çözme becerilerinin kadın öğrencilere göre daha yüksek olduğu sonucuna varmıştır. Tekin'in (2009) ferdi ve takım sporları yapan erkek ve kadın sporcuların zeka türlerine ilişkin yaptığı çalışmada erkek sporcuların matematiksel zeka alanlarından aldıkları puanlar daha yüksek çıkmıştır. Dexter (1999) spor bilgisi, spor performansı ve akademik başarı arasındaki ilişkiyi inceleyen araştırmasında erkek öğrencilerin kadın öğrencilere göre daha yüksek spor bilgisine sahip oldukları bunun devamında da spor performansı ve akademik başarıları olarak daha üstün 
oldukları sonucuna varmıştır. $\mathrm{Bu}$ bulgular çalışmada ulaşılan sonuçlarla benzerlik göstermektedir.

Araştırmaya katılan sporcuların üniversite türü değişkenine göre aldıkları sonuçlar incelendiğinde bu değişkenle ilgili herhangi bir farklılığın olmadığı görülmüştür. İstatistiksel sonuçlara göre devlet üniversitelerine devam eden öğrencilerin ölçekten aldıkları ortalama puanlar özel üniversitelere devam eden öğrencilere göre yüksek olsa da bu fark istatistiksel açıdan bir farklılık göstermemektedir.

Araştırmaya katılan sporcuların spor dalı değişkenlerine göre matematiksel düşünme ölçeğinden aldıkları puanlara bakıldığında salon futbolu sporunu yapan sporcuların puanları (sıra ortalaması $143,77)$ diğer gruplara göre anlamlı derecede $(p<, 05)$ yüksek çıkmıştır. Futbol ve basketbol sporunu yapanlar birbirine yakın değerde iken en düşük puana sahip olan katılımcılar voleybol sporunu yapanlardır. Elde edilen bulgulara göre konsantrasyon, hız, çabukluk, çeviklik, reaksiyon ve ani karar verme gibi parametrelerin gerektirdiği spor dallarından biri ola salon futbolu sporunu yapan katılımcıların matematiksel düşünme düzeyleri diğer spor dallarını yapan öğrencilere göre yüksek bulunmuştur. Salon futbolunu yapan öğrencilerin matematiksel düşünme becerilerinin yüksek çıkması bu sporun gereklilikleriyle ilişkilendirilebilir.

Takım sporları yapan sporcular arasında matematiksel düşünme ölçeği alt boyutları üst düzey düşünme eğilimi puanlarına bakıldığında salon futbolu 143,00, basketbol 86,26 ve futbol 81,36, voleybol 49,41'dir. Ak1l yürütme alt boyutunda salon futbolu 144,32, basketbol 88,96, futbol 75,93 ve voleybol 51,10'dur. Matematiksel düşünme becerisi değerleri salon futbolu 143,11, basketbol 88,76, futbol 78,29 ve voleybol 50,47'dir. Problem çözme alt boyutuna göre salon futbolu 141,24, basketbol 92,79, futbol 73,62 ve voleybol 54,51'dir. Önal, İnan ve Bozkurt (2017) sporcuların matematiksel düşünme becerilerini araştırdıkları çalışmalarında takım sporu yapan sporcular içerisinde futbol branşıyla ilgilenen sporcuların diğer branşlara göre daha yüksek puanlar aldıklarını tespit etmişlerdir. Singh ve diğerlerinin (2015) voleybol ve futbol sporuyla ilgilenen farklı yaş gruplarındaki sporcuların mental becerileriyle ilgili araştırmasında okul çağındaki sporculardan futbolla ilgilenen sporcuların voleybolla ilgilenen sporculara göre daha yüksek puan aldıkları görülmüştür. Bu bulgu çalışmanın bulgularıyla örtüşmektedir.

Fiziksel aktivite ile matematiksel beceri arasındaki ilişkiyi inceleyen çalışmalarda spor yapan bireylerin matematiksel becerilerine olumlu katkı sağladığını gösteren çalışmalara rastlanmıştır. Bunlardan, Canan ve Ataoğlu'nun (2010) sporcularla yaptıkları araştırmada takım sporları yapan katılımcıların matematiksel düşünme becerilerinin alt boyutu olarak değerlendirilen problem çözme becerilerinin yüksek olduğu sonucuna varılmıştır. Vazou ve Skrade'nin (2016) 
çalışmalarında fiziksel aktiviteyle entegre edilmiş ders ortamında öğrencilerin matematik performansları değerlendirilmiştir. Deneysel olarak desenlenen çalışmada fiziksel aktivitenin matematik performansına olumlu katkı sağladığı görülmüştür. Dexter (1999) spor bilgisi, spor performansı ve akademik başarı arasındaki ilişkiyi inceleyen araştırmasında spor performansı ile matematik ve İngilizce dersi başarıları arasında pozitif ilişki bulmuştur.

Yaş değişkeniyle ilgili bulgular incelendiğinde sporculardan 24-27 yaş grubunda olanların matematiksel düşünme beceri puanlarının daha yüksek olduğu görülmüştür. $\mathrm{Bu}$ sonuca göre öğrencilerin yaş düzeyinin arttıkça matematiksel düşünme becerilerinin arttığ1 söylenebilir. Sporcuların deneyimleriyle ilgili bulgularda ise 0-5 yılları arasında spor yapan öğrencilerin sonuçları diğer gruplara göre daha yüksek çıkmıştır.

Matematiksel düşünme becerileri yönünden üniversiteler arası müsabakalara katılan ve takım sporları ile ilgilenen sporcuları incelenen bu araştırmada elde edilen ve literatürdeki araştırma sonuçlarına göre; üniversite eğitimine kadar ki süreçte spor faaliyetlerinde düşünme becerilerinin tüm boyutlarına yönelik etkinlikler, çalışmalar çeşitlendirilmeli, arttırılmalıdır. Bu araştırmada seçilen spor branşları dışındaki branşlarda da benzer çalışmalar yapılabilir. Özellikle bu alanlarda yapılacak yeni çalışmaların üniversitelerin takım müsabakalarında ki sportif başarılarına, sporcuların kişisel gelişimlerine ve almış oldukları eğitime katkılar sağlayacağı umulmaktadır.

\section{Kaynakça}

Anan, F., Ataoğlu, A. (2010) “Anksiyete, Depresyon Ve Problem Çözme Becerisi Algısı Üzerine Düzenli Sporun Etkisi”. Anadolu Psikiyatri Dergisi, 11, 38-43.

Biltzer, R. (2003) Thinking Mathematically, New Jersey 07458, Prentice Hall,

Brown, R. (1965) Social Psychology. New York, Free Press.

Bukova E., Alkan H. (2003) "Matematik Öğretiminde Öğrencilerde Matematiksel Gücün Gelişimine Yönelme”. XII. Ë̆itim Bilimleri Kongresi 15-19 Ekim, Antalya.

Bukova-Güzel, E. (2008) "Yapılandırmacı Öğrenme Yaklaşımının Matematik Öğretmen Adaylarının Matematiksel Düşünme Süreçlerine Olan Etkisi”. e-Journal of New World Sciences Academy, 4(3), 678-688.

Cai, J. (2003) "Setting the Record Straight or Setting Up a Research Agenda?-A Review of Standards-Based School Mathematics Curricula: What Are They? What Do Students Learn?", Journal for Research in Mathematics Education, 34(3), 260-265.

Canan, F. ve Ataoğlu, A. (2010). Anksiyete, depresyon ve problem çözme becerisi algısı üzerine düzenli sporun etkisi. Anadolu Psikiyatri Dergisi. 11(1). 38-43.

Dexter, T. (1999) "Relationships between sport knowledge, sport performance and academic ability: Empirical evidence from GCSE Physical Education". Journal of Sports Sciences, 17:4, 283-295

Ersoy, E. (2002). Üst Düzey Düşünme Becerilerinin Probleme Dayalı Öğrenme Sürecinde Duyuşsal Kazanımlara Etkisi. Yayınlanmamış Doktora Tezi. Dokuz Eylül Üniversitesi Eğitim Bilimleri Enstitüsü.

Ferri, R.B. (2003) "Mathematical Thinking Styles- An Emprical Study". European Research In Mathematics Education III. 28 Şubat- 3 Mart, Bellaria.

Henderson, P. B., Hitchner, L., Fritz, S. J., Marion, B., Scharff, C., Hamer, J. ve Riedesel, C. (2002). "Materials Development in Support of Mathematical Thinking”. SIGCSE Bull., 35(2), 185-190.

Karasar, N. (2009). Bilimsel Araştırma Yöntemi. Ankara: Nobel Yayıncılık.

Küçük, V., Koç, H. (2004) “Psiko-Sosyal Gelişim Süreci İçerisinde İnsan Ve Spor İlişkisi”. Dumlupınar Üniversitesi Sosyal Bilimler Dergisi. 10, 131-142.

Metan H., Küçük, V. (2017) “12-14 Yaş Grubu Düzenli Spor Yapan Ve Yapmayan Bireylerin Çoklu Zekâ Yönüyle Karşılaştırılması”. Uluslararası Sosyal Araştırmalar Dergisi, 49, 327-333. 
Millî Eğitim Bakanlığı (2013) Talim Ve Terbiye Kurulu Başkanlığı Ortaöğretim Matematik Dersi Öğretim Programi, Ankara.

National Council of Teachers of Mathematics (2000). Principles and Standarts for School Mathematics, Reston, VA: NCTM.

Önal, H., İnan, M. ve Bozkurt, S. (2017) "A Research on Mathematical Thinking Skills: Mathematical Thinking Skills of Athletes in Individual and Team Sports" Journal of Education and Training Studies, 5(9), 133139.

Salar, B., Hekim, M., Tokgöz, M. (2012) "15-18 Yaş Grubu Takım ve Ferdi Spor Yapan Bireylerin Duygusal Durumlarının Karşılaş̧ırılması” Mehmet Akif Ersoy Üniversitesi, Sosyal Bilimler Enstitüsü Dergisi, 4 (6), 123-135.

Sevgen, B. (2002) "Matematiksel Düşünce Yapısı ve Gelişimi". V. Ulusal Fen Bilimleri Ve Matematik Eğitimi Kongresi, 16-18-Eylül, Ortadoğu Teknik Üniversitesi, Ankara.

Singh J., Singh C. ve Singh M (2015). Mental Skills : A Comparison between Volleyball and Football Players. International Multidisciplinary e -Journal. 4 (3). 122-128.

Spyridoula, V. ve Miriam A.B., S. (2016) "Intervention integrating physical activity with math: Math performance, perceived competence, and need satisfaction". International Journal of Sport and Exercise Psychology, $508-522$

Tall, D. (1995) "Cognitive Growth İn Elementary And Advenced Mathematical Thinking" International Conference For The Psychology Of Mathematical Education I, Recife, Brazil.

Tekin, M. (2009). "Ferdi Ve Takım Sporlarında Erkek Ve Kız Sporcuların Farklı Zekâ Tiplerindeki Seviyelerinin Karşlaştırılması". Beden Ĕgitimi ve Spor Bilimleri Dergisi. 11 (4). 29-51.

Türkçapar, Ü. (2009) "Beden Eğitimi Spor Yüksek Okulu Öğrencilerinin Farklı Değişkenler Açısından Problem Çözme Becerileri”. Ahi Evran Üniversitesi Kırşehir Eğitim Fakültesi Dergisi (KEFAD) 10 (1) 129-139.

Umay, A. (1996) "Matematik Eğitimi ve Ölçülmesi”. Hacettepe Üniversitesi Eğitim Fakültesi Dergisi, 12, 145-149.

Vazou, S. ve Skrade, M. A. B. (2017). "Intervention integrating physical activity with math: Math performance, perceived competence, and need satisfaction". International Journal of Sport and Exercise Psychology, 15(5), 508-522. 